\title{
Nuclear DNA introgression across a Pyrenean hybrid zone between parapatric subspecies of the grasshopper Chorthippus parallelus
}

\author{
PATRICIA VAZQUEZ, STEVEN J. B. COOPER, JAIME GOSALVEZ† \& \\ GODFREY M. HEWITT* \\ School of Biological Sciences, University of East Anglia, Norwich NR4 7TJ, U.K. and tDepartamento de Biologia, \\ Universidad Autonoma de Madrid, E-28049, Madrid, Spain
}

\begin{abstract}
Two parapatric subspecies of the European grasshopper Chorthippus parallelus meet along the Pyrenees and form a hybrid zone. A nuclear DNA sequence marker (cpnl-1), involving the presence or absence of a 5 bp insertion, was found to differentiate between the two subspecies along either side of the High Pyrenees but further electrophoretic and sequence analyses revealed that considerable mixing of the subspecific genomes had occurred towards the western and eastern ends of the Pyrenees. The cline for this marker was relatively narrow in two adjoining western central high cols (Peyrelue: $9.7 \mathrm{~km}$ and Portalet: $13.3 \mathrm{~km}$ ) but was significantly wider in another central high col towards the east (Quillane: $42.3 \mathrm{~km}$ ), indicating that a different combination of forces has been operating on this locus in different regions of the Pyrenees.
\end{abstract}

Keywords: Chorthippus parallelus, grasshopper, hybrid zone, nuclear DNA, polymerase chain reaction, postglacial expansion.

\section{Introduction}

Hybrid zones are narrow regions where genetically distinct populations meet, mate and produce hybrids (Barton \& Hewitt, 1985) and they have been variously described as 'natural laboratories for evolutionary studies' (Hewitt, 1988) and 'windows on the evolutionary process' (Harrison, 1990). This is because they offer excellent opportunities to study many aspects of genetic divergence and speciation, gene flow and introgression, natural selection and adaptation. In recent years there has been an explosion of multidisciplinary studies on particular species (Harrison, 1993) that aim to identify the factors involved in maintaining and generating genome subdivision and thereby facilitate our understanding of the process of speciation. One such long-term study involves the meadow grasshopper Chorthippus parallelus.

C. parallelus occurs in Western Europe as two subspecies, C. p. erythropus south of the Pyrenees in Spain and Portugal, and C. p. parallelus to the north in France and beyond. Where these subspecies meet along the length of the Pyrenees a hybrid zone has been identi-

*Correspondence. fied (Butlin \& Hewitt, 1985a; Hewitt, 1993) which probably formed some 9-12000 years ago (BP) following range expansion of the two subspecies and secondary contact as the ice retreated after the last glaciation. The two subspecies differ in many characters including morphology, behaviour, allozymes and chromosomes (Butlin \& Hewitt, 1985a, b; Gosálvez et al., 1988; Butlin \& Ritchie, 1991), and these have been used to measure the extent of mixing and introgression between the two genomes in several places along the Pyrenees. In the lower hills at the ends of the mountain range morphological measures suggest possible mixing of the two subspecific forms. In two cols (passes) in the High Pyrenees (Col du Portalet, south of Pau and Col de la Quillane, south of Carcassonne) these studies have been much more detailed, describing varying cline widths for the change from one pure subspecies character to the other (Butlin et al., 1991; Hewitt, 1993).

In general, these clines for different characters are centred near the summit of the col, but have variable widths demonstrating that introgression for the genes controlling them has progressed differently after secondary contact of the two subspecies around 9000 $\mathrm{BP}$. The width of such a cline is determined by the rate 
and form of dispersal of the insect, the selection operating on the character and its genetic basis, and the number of generations over which these have operated (Barton \& Hewitt, 1989; Hewitt, 1993). Thus broad clines are produced by long-distance dispersal of neutral alleles over many generations, and narrow clines are produced by limited dispersal of genes showing heterozygote disadvantage. These latter clines are called tension zones and reach a balance between dispersal and selection in relatively few generations (Barton \& Hewitt, 1989). $F_{1}$ male hybrids between $C$. p. parallelus and C. p. erythropus are sterile and therefore would form a tension zone for those genes involved (Hewitt et al., 1987; Virdee \& Hewitt, 1990).

Our understanding of the dynamics of such hybridizations will clearly be advanced if we have single gene differences available for mapping, experimentation and analysis. An excellent example of this is seen in the fire bellied toad Bombina bombina/variegata where a suite of allozyme markers has been employed (Szymura \& Barton, 1986, 1991). Despite examining some 40 allozyme systems in $C$. parallelus only two clear diagnostic loci were found. However, as a result of a comparison of DNA differences between $C . p$. parallelus and C. $p$. erythropus we have found clear subspecific sequence haplotypes in a noncoding nuclear DNA fragment (Cooper \& Hewitt, 1993). As well as providing a locus for analysis of nuclear introgression across the Pyrenees between the two subspecies, it also allows a measure of sequence divergence and construction of a phylogeography. In particular, it is pertinent to ask: (i) are populations of each subspecies from either side of the Pyrenees homogeneous, (ii) is there evidence of introgression and (iii) do their DNA sequences indicate one or two postglacial invasions?

\section{Materials and methods}

\section{Geographical sampling}

Adult C. parallelus were collected in July/August 1991-1993 from 15 populations on the northern (French) and southern (Spanish) sides of the Pyrenees (Fig. 1a) and from a further 25 populations through the Col du Portalet (Fig. 1b) and Col de la Quillane (Fig. 1c). Whole grasshopper bodies were stored either frozen at $-70^{\circ} \mathrm{C}$ (1991 samples) or in 100 per cent alcohol at $-20^{\circ} \mathrm{C}$ (1992 samples). In addition to the above samples, testes and hind legs from grasshoppers collected in 1990 for cytological studies of the hybrid zone at Col du Portalet and Col de la Quillane were also utilized as a source of DNA. These samples had been stored in $3: 1$ ethanol-acetic acid at $-20^{\circ} \mathrm{C}$.

\section{DNA extraction}

DNA was extracted from hind legs or testes using the Chelex 100 (Biorad) procedure as described by Cooper \& Hewitt (1993).

\section{Polymerase chain reaction (PCR) amplification of grasshopper DNA}

Two oligonucleotide primers, cno76 and cno77, were used to PCR amplify a 393-bp noncoding nuclear DNA (cpnl-1) segment for each grasshopper DNA sample as described by Cooper \& Hewitt (1993). One $\mu \mathrm{L}$ of the amplified products was used to initiate PCR amplifications with a second set of internal primers:

cno2SB ( $5^{\prime}$-GCCATCTCCTCTCTCTGTCC-3') cnoINS.P ( $5^{\prime}$-GTAATTTTGTGGTAACTTGCC-3').

The second PCR amplification was carried out in a 50 $\mu \mathrm{L}$ reaction volume using 1 unit of Taq polymerase and $1 \times$ standard buffer (Promega) containing $1.5 \mathrm{~mm}$ $\mathrm{MgCl}_{2}$ for 30 cycles $\left(94^{\circ} \mathrm{C}, 30 \mathrm{~s} ; 60^{\circ} \mathrm{C}, 30 \mathrm{~s} ; 72^{\circ} \mathrm{C}\right.$, 30 s) using a Perkin Elmer thermocycler.

\section{Gel electrophoresis}

PCR amplified fragments from individuals with or without the $5 \mathrm{bp}$ insertion ( $128 \mathrm{bp}$ and $123 \mathrm{bp}$ ) were resolved by electrophoresis in 15 per cent nondenaturing acrylamide gels in $0.5 \times \mathrm{TBE}$ ( $45 \mathrm{~mm}$ Tris, 44 mM boric acid, 1 mM EDTA) and visualized by ethidium bromide staining as described by Sambrook et al. (1989).

\section{DNA sequencing}

The cpnl-1 segment was sequenced from individuals in populations at Ich, Erra, Erro and Par, using the procedures described by Cooper \& Hewitt (1993).

\section{Fitting clines}

A tanh curve (Barton \& Gale, 1993) was fitted to the data and cline widths estimated by the method of maximum likelihood assuming a binomial error distribution, using GENSTAT 5 (see Butlin et al., 1991 for full details).

\section{Results}

Previous analyses of an anonymous noncoding nuclear DNA marker (cpnl-1) in C. parallelus from populations in Spain and France revealed that the majority of cpnl-1 sequence haplotypes detected in Spain contained a $5 \mathrm{bp}$ insertion which was absent in haplotypes 
(a)
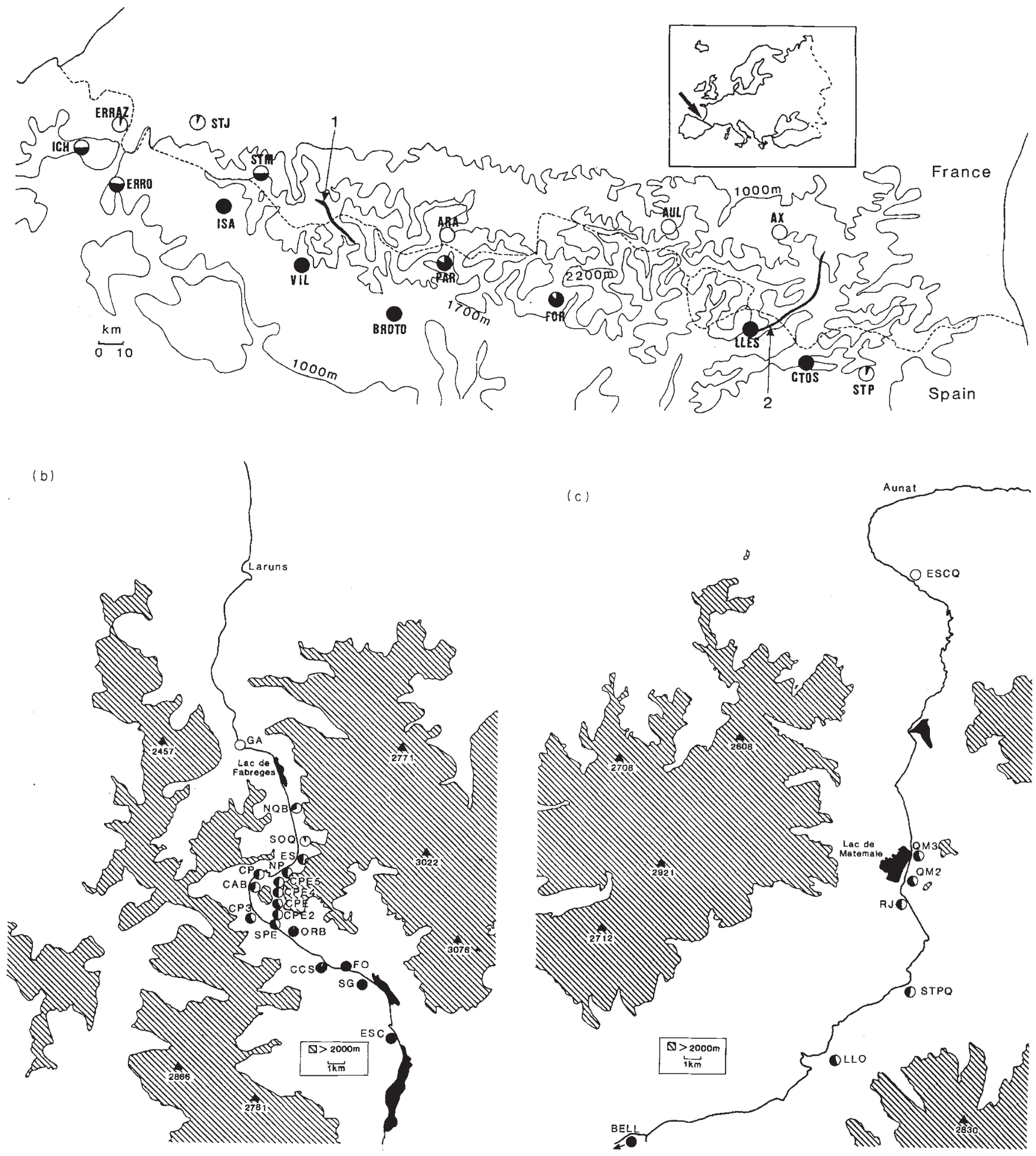

Fig. 1 Frequency distribution of the insertion/deletion alleles (I5 and I0) in C. parallelus from populations (a) either side of the Pyrenees, (b) through Col du Portalet and the adjoining Col de Peyrelue and (c) Col de la Quillane. The proportion of individuals with the $\mathrm{I} 5$ allele is given by the black portion of the pie diagrams (see Tables 2 and 3 for further details on frequencies and distances between populations). Also shown in Fig. 1(a) are the position of Col du Portalet (1) and Col de la Quillane (2). Grid references for each population are available upon request to the authors. 
in France (Cooper \& Hewitt, 1993). In Spanish populations in the High Pyrenees the insertion was found to occur at a frequency of 96 per cent. It therefore provides a useful marker sequence to investigate nuclear DNA introgression in detail across the Pyrenees between the two subspecies $C$. p p parallelus and $C$. $p$. erythropus. In order to detect the $5 \mathrm{bp}$ insertion/ deletion from large numbers of grasshoppers, a rapid protocol was developed in which a small region of the cpnl-1 segment (123-128 bp) was PCR amplified using internal primers and alleles ( 5 bp insertion, 15 and no insertion, $\mathrm{I} 0$ ) were distinguished by standard polyacrylamide gel electrophoresis.

To test whether all heterozygous individuals could be identified using the above procedure, the 123/ $128 \mathrm{bp}$ fragment was amplified from $20 \mathrm{C}$. parallelus parallelus $/ C$. parallelus erythropus $\mathrm{F}_{1}$ hybrids in triplicate. Analysis by electrophoresis revealed two visible DNA fragments (123 bp (I0) and $128 \mathrm{bp}(\mathrm{I} 5))$ in 80,70 and 90 per cent of individuals for each of the three replicates, respectively (Fig. 2 and Table 1). Overall, 100 per cent of all heterozygous individuals were detected after two replications of the procedure. These results indicate that the PCR is often amplifying one of the strands more than the other, but this appears to be at random. Therefore, to avoid errors in the misclassifi-

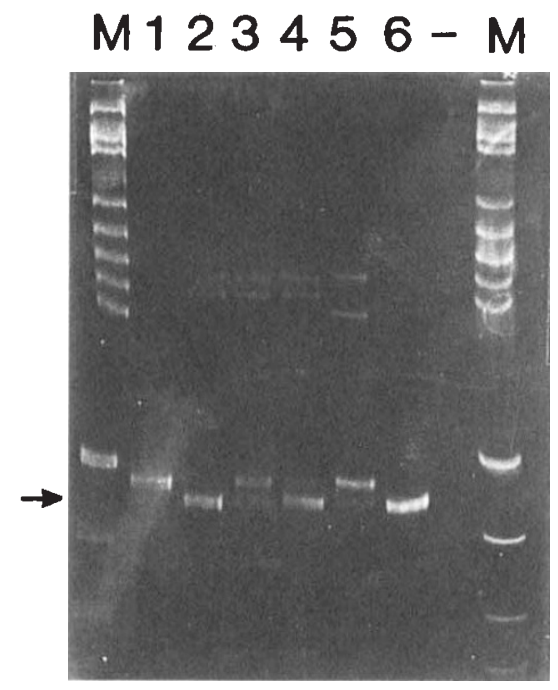

Fig. 2 Polyacrylamide gel showing separation of the $123 \mathrm{bp}$ (no insertion) and $128 \mathrm{bp}$ (insertion) fragments from $C$. parallelus $\mathrm{F}_{1}$ hybrids (arrow). Lanes: $\mathrm{M}, \mathrm{pBR} 322$ cut with HaeIII; 1, pure-bred $C$. parallelus parallelus; 2-5, hybrid individuals; 6, pure-bred C. parallelus erythropus; -, negative control. Extra fragments with a slower mobility were also observed in each lane of the hybrid individuals. These are likely to be double-stranded DNA fragments resulting from heteroduplex formation between single strands with and without the 5 bp insertion. cation of genotypes, all DNA samples from each population were analysed at least three times and more than three times if faint bands were detected after acrylamide electrophoresis.

\section{Genetic distinctness of Spanish and French C. parallelus}

To establish whether Spanish and French grasshoppers were genetically distinct from each other over the entire length of the Pyrenees, grasshoppers were collected from 11 Spanish and five French populations (Fig. 1a) and analysed for the presence or absence of the $5 \mathrm{bp}$ insertion.

Populations on the French side in the High Pyrenees (ARA, AUL and AX) were fixed for I0 (frequency of 1) whilst comparable populations on the Spanish side were fixed for the alternative allele I5 (Fig. 1a and Table 2). Two Spanish populations near the centre of the Pyrenees (PAR and FOR) gave a frequency of 0.14 and 0.10 , respectively, for I0. DNA sequencing of the cpnl-1 segment from grasshoppers in PAR revealed that they contained a haplotype (pna12) which is found exclusively in Spanish populations

Table 1 Allelic fragments I0 (no insertion) and I5 (5 bp insertion) detected in GA/SG $F_{1}$ hybrid individuals of grasshoppers (Chorthippus parallelus) by polyacrylamide gel electrophoresis in three independent replicates

\begin{tabular}{cccc}
\hline Individual & 1st replicate & 2nd replicate & 3rd replicate \\
\hline 1 & I5 & - & - \\
2 & I0 & I5 & - \\
3 & - & - & I5 \\
4 & - & - & - \\
5 & - & I0 & - \\
6 & - & - & - \\
7 & - & - & I0 \\
8 & - & I5 & - \\
9 & - & - & - \\
10 & I5 & - & - \\
11 & - & - & - \\
12 & - & - & - \\
13 & - & - & - \\
14 & I0 & I5 & - \\
15 & - & - & - \\
16 & - & I5 & - \\
17 & - & - & - \\
18 & - & - & - \\
19 & - & - & - \\
20 & - & I0 & - \\
\hline
\end{tabular}

- , both allelic fragments ( $\mathrm{I} 0$ and $\mathrm{I} 5)$ were detected in that individual. 
(Cooper \& Hewitt, 1993). Therefore the presence of an I0 in these populations is not indicative of introgression of French haplotypes across the Pyrenees. These data indicate that Spanish and French grasshoppers in the centre of the Pyrenees (High Pyrenees) are genetically distinct from each other.

Populations at the eastern and western ends of the Pyrenees were found to contain a mixture of both $\mathrm{I} 0$ and I5 at polymorphic frequencies (Table 2). One eastern end Spanish population (STP) contained I0 at a frequency of 0.8 , while an adjacent Spanish population (CTOS) was fixed for I5. DNA sequencing of the cpnl-1 segment in two individuals from STP indicated that they contained both French and Spanish haplotypes (Table 2). At the western end of the Pyrenees, three Spanish populations ERRAZ, ERRO and $\mathrm{ICH}$ were also found to contain $\mathrm{I} 0$ at a relatively high frequency (ERRAZ freq. (I0) $=0.88$, ERRO freq. $(\mathrm{I} 0)=0.36$, ICH freq. $(\mathrm{I} 0)=0.44)$. In addition, I5 was detected in one French population (STJ) at a frequency of 0.1 . DNA sequencing of the cpnl-1 fragment from five individuals at ERRAZ and four individuals from ICH confirmed they contained several haplotypes found exclusively in French populations (Table 2; Cooper \& Hewitt, 1993). These results indicate that in the eastern (Catalan region) and western (Basque region) foothills of the Pyrenees, French and Spanish forms of $C$. parallelus are not genetically distinct and appear to contain a mixture of haplotypes.

\section{Transects through the Col du Portalet and Col de la Quillane}

The frequency of the I0 and I5 alleles was determined from 18 populations in transects through the $\mathrm{Col} \mathrm{du}$ Portalet and Col de Peyrelue in the central Pyrenees with 8-15 individuals analysed for each population (Table 3 and Fig. 1b). The French population Gabas (GA) at the end of the transect was fixed for I0, whilst comparable populations at the end of the transect on the Spanish side (FO, SG and ESC) were fixed for the alternative allele, I5. Between these Spanish and French populations a cline in the frequencies of $\mathrm{I} 0$ and I5 was observed (Figs 1b and 3). Through Col du Portalet an estimated cline width of $13.3 \mathrm{~km}$ (SE士 $1.73 \mathrm{~km}$ ) was obtained, with the cline centred $21.0 \mathrm{~km}$ $( \pm 0.53 \mathrm{~km})$ from Laruns, between populations at $\mathrm{CP}$ and NP (Figs $1 \mathrm{~b}$ and 3a). The Col de Peyrelue branches from the Col du Portalet just after the NP collection site, runs parallel for several kilometres (populations CPE5, CPE4, CPE, CPE2) and then rejoins it near the SPE collection site (Fig. 1b). It has an estimated cline width of $9.7 \mathrm{~km}( \pm 1.36 \mathrm{~km})$, with the cline centred $20.0 \mathrm{~km}( \pm 0.36 \mathrm{~km})$ from Laruns, approximately $280 \mathrm{~m}$ north of NP (Figs $1 \mathrm{~b}$ and $3 \mathrm{~b}$ ).

The frequencies of the I0 and I5 alleles were also determined from seven populations in a transect through the Col de la Quillane towards the eastern end of the Pyrenees, with five individuals analysed per

Table 2 Frequency of the 'no insertion' allele (I0) and genotypes of individuals in populations along the Pyrenees (location as specified in Fig. 1)

\begin{tabular}{lcccccc}
\hline & & \multicolumn{3}{c}{ Genotypes } & & \\
\cline { 3 - 4 } Population & Frequency $(\mathrm{I} 0)$ & I5/I5 & I5/I0 & I0/I0 & $\begin{array}{c}\text { Sample } \\
\text { size }\end{array}$ & $\begin{array}{c}\text { cpnl-1 haplotypes } \\
\text { detected by sequencing* }\end{array}$ \\
\hline ERRAZ/Sp & 0.88 & 0 & 2 & 6 & 8 & $1,2,6,12,26$, \\
ICH/Sp & 0.44 & 4 & 2 & 3 & 9 & - \\
ERRO/Sp & 0.36 & 6 & 2 & 3 & 11,20 \\
ISA/Sp & 0.00 & 7 & 0 & 0 & 7 & - \\
VIL/Sp & 0.00 & 10 & 0 & 0 & 10 & - \\
BROTO/Sp & 0.00 & 2 & 0 & 0 & 2 & 12,18 \\
PAR/Sp & 0.14 & 5 & 2 & 0 & 7 & - \\
FOR/Sp & 0.10 & 8 & 2 & 0 & 10 & - \\
LLES/Sp & 0.00 & 11 & 0 & 0 & 11 & - \\
CTOS/Sp & 0.00 & 10 & 0 & 0 & 10 & - \\
STP/Sp & 0.80 & 2 & 0 & 8 & 10 & - \\
STJ/F & 0.90 & 0 & 1 & 4 & 5 & - \\
STM/F & 0.44 & 4 & 2 & 3 & 9 & - \\
ARA/F & 1.00 & 0 & 0 & 10 & 10 & - \\
AUL/F & 1.00 & 0 & 0 & 9 & 9 & - \\
AX/F & 1.00 & 0 & 0 & 3 & 3 & - \\
\hline
\end{tabular}

*Haplotypes 1, 2, 4 are French; haplotypes 6, 12, 20 are northern Spanish; haplotype 11 is Spanish (not detected in northern Spain); haplotype 26 is found in both France and northern Spain. See Cooper \& Hewitt (1993) for the sequence of each haplotype. 
Table 3 Frequency distribution of the 'no insertion' allele (I0) from C. parallelus in three Pyrenean cols, Col du Portalet (Po), Col de Peyrelue (Pe)* and Col de la Quillane

\begin{tabular}{|c|c|c|c|c|}
\hline Population & \multicolumn{2}{|c|}{$\begin{array}{l}\text { Distance along col } \\
(\mathrm{km})\end{array}$} & $\begin{array}{l}\text { Sample } \\
\text { size }\end{array}$ & $\begin{array}{l}\text { Frequency } \\
\quad(\mathrm{I} 0)\end{array}$ \\
\hline Portalet/Peyrelue & \multicolumn{2}{|c|}{ from Laruns } & & \\
\hline GA & \multicolumn{2}{|c|}{10.9} & 10 & 1.00 \\
\hline NQB & \multicolumn{2}{|c|}{16.3} & 15 & 0.67 \\
\hline SOQ & \multicolumn{2}{|c|}{18.2} & 8 & 0.81 \\
\hline ES & \multicolumn{2}{|c|}{19.2} & 10 & 0.55 \\
\hline NP & \multicolumn{2}{|c|}{20.2} & 8 & 0.50 \\
\hline $\mathrm{CP}(\mathrm{Po})$ & \multicolumn{2}{|l|}{$21.2(\mathrm{Po})$} & 9 & 0.56 \\
\hline $\mathrm{CAB}(\mathrm{Po})$ & \multicolumn{2}{|l|}{$22.0(\mathrm{Po})$} & 9 & 0.61 \\
\hline $\mathrm{CP} 3(\mathrm{Po})$ & \multicolumn{2}{|l|}{$24.0(\mathrm{Po})$} & 10 & 0.35 \\
\hline CPE 5 (Pe) & \multicolumn{2}{|r|}{$20.6(\mathrm{Pe})$} & 10 & 0.55 \\
\hline $\mathrm{CPE} 4(\mathrm{Pe})$ & \multicolumn{2}{|r|}{$20.9(\mathrm{Pe})$} & 10 & 0.50 \\
\hline $\mathrm{CPE}(\mathrm{Pe})$ & \multicolumn{2}{|r|}{$21.3(\mathrm{Pe})$} & 10 & 0.35 \\
\hline $\mathrm{CPE} 2(\mathrm{Pe})$ & \multirow{2}{*}{\multicolumn{2}{|c|}{$\begin{array}{ll} & 21.5(\mathrm{Pe}) \\
25.0(\mathrm{Po}) & 21.8(\mathrm{Pe})\end{array}$}} & 10 & 0.45 \\
\hline SPE & & & 10 & 0.35 \\
\hline ORB & \multicolumn{2}{|c|}{$25.9(\mathrm{Po}) \quad 22.7(\mathrm{Pe})$} & 10 & 0.05 \\
\hline CCS & \multicolumn{2}{|c|}{$28.9(\mathrm{Po}) \quad 25.7(\mathrm{Pe})$} & 15 & 0.17 \\
\hline FO & \multicolumn{2}{|c|}{$29.9(\mathrm{Po}) \quad 26.7(\mathrm{Pe})$} & 10 & 0.00 \\
\hline SG & \multicolumn{2}{|c|}{$30.7(\mathrm{Po}) \quad 27.4(\mathrm{Pe})$} & 10 & 0.00 \\
\hline ESC & \multicolumn{2}{|c|}{$34.0(\mathrm{Po}) \quad 30.7(\mathrm{Pe})$} & 10 & 0.00 \\
\hline Quillane & \multicolumn{2}{|c|}{ from Aunat } & & \\
\hline $\mathrm{ESCQ}$ & \multicolumn{2}{|c|}{6.6} & 5 & 1.00 \\
\hline QM3 & \multicolumn{2}{|c|}{23.4} & 5 & 0.40 \\
\hline QM2 & \multicolumn{2}{|c|}{25.0} & 5 & 0.40 \\
\hline $\mathrm{RJ}$ & \multicolumn{2}{|c|}{26.3} & 5 & 0.50 \\
\hline STPQ & \multicolumn{2}{|c|}{32.0} & 5 & 0.60 \\
\hline LLO & \multicolumn{2}{|c|}{38.5} & 5 & 0.40 \\
\hline BELL & \multicolumn{2}{|c|}{64.0} & 5 & 0.00 \\
\hline
\end{tabular}

*Note that Col de Peyrelue branches from Col du Portalet at $\mathrm{NP}$ and then rejoins near SPE.

population (Fig. 1c and Table 3). The French population ESCQ at the end of the transect was fixed for I0 whilst the Spanish population BELL was fixed for the alternative allele I5. Between these two populations a cline in the frequencies of the I0 and I5 alleles was detected (Figs $1 \mathrm{c}$ and $3 \mathrm{c}$ ) with an estimated cline width of $42.3 \mathrm{~km}( \pm 15.7 \mathrm{~km})$, centred just south of RJ, approximately $27.9 \mathrm{~km}( \pm 2.97 \mathrm{~km})$ from Aunat (Fig. 1c). To test whether this is significantly wider than the cline through Col du Portalet and Col de Peyrelue, the Quillane data were reanalysed using a fixed cline width of $15 \mathrm{~km}$ (conservative estimate of the cline width at Col du Portalet). The centre was estimated to be 27.7 $\mathrm{km}$ with a likelihood of -12.92 , compared with -4.21 using a width of $42.3 \mathrm{~km}$. The difference between these two likelihood values is greater than 2 likelihood units which provides evidence that the esti- mated cline width at Col de la Quillane is significantly greater than the cline width at $\mathrm{Col}$ du Portalet and $\mathrm{Col}$ de Peyrelue.

\section{Discussion}

The populations of $C$. parallelus from the Spanish side of the High Pyrenean mountains are characterized by a $5 \mathrm{bp}$ insertion in a noncoding nuclear DNA fragment that is absent in populations along the French side. This I5 allele is fixed in most of the Spanish population samples, and in those where it is not the 10 alleles are distinctly Spanish in their DNA sequence. This DNA fragment (cpnl-1) sequence has been compared in $C$. $p$. erythropus from across Spain and $C$. $p$. parallelus from across France (Cooper \& Hewitt, 1993). It has diverged considerably (up to 3.5 per cent) in the two subspecies and this clearly indicates that the two genomes have been essentially separate for the Holocene and a considerable part of the Pleistocene, during which several ice ages have occurred. This distinctness of the Spanish cpnl-1 sequences allows a clear recognition of $\mathrm{I} 0$ alleles as either Spanish or French, and hence the conclusion that populations from the Spanish side of the High Pyrenees do not contain French $\mathrm{I} 0$ alleles.

In contrast, the populations sampled from the western (Basque) and eastern (Catalan) ends of the Pyrenean chain appear to contain mixtures of French and Spanish sequences. Furthermore, from the populations analysed so far this mixing occurs over quite a wide region and is very different from the clear narrow
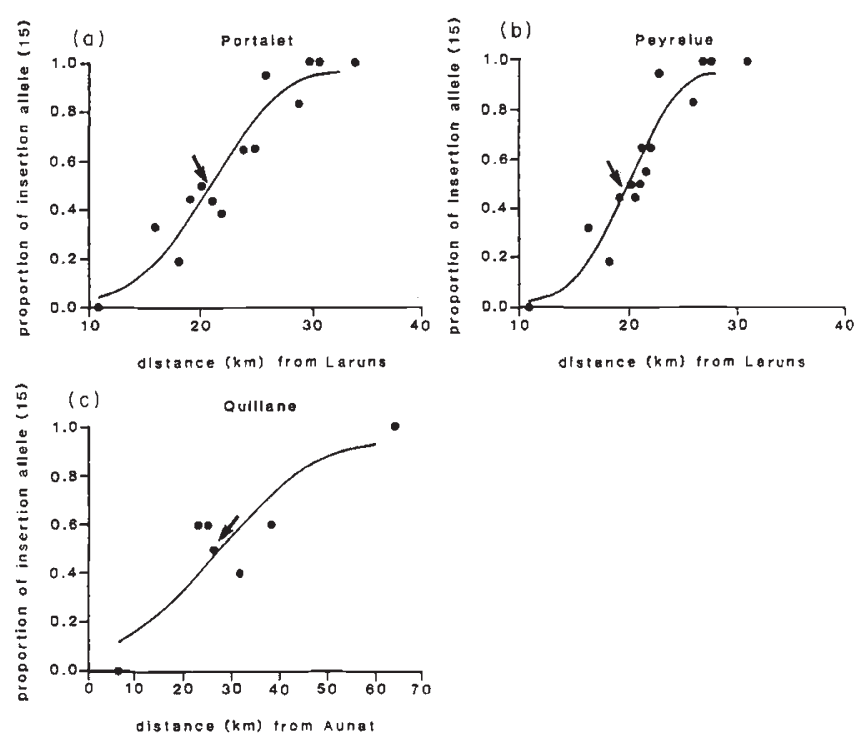

Fig. 3 Fitted clines to frequency data of the $15 / 10$ alleles in C. parallelus from populations at Portalet (a), Peyrelue (b) and Quillane (c). Arrows indicate the cline centres. 
distinction between the French and Spanish sides of the High Pyrenees. Earlier morphological observations (Butlin \& Hewitt, 1985a) and current cytological/ morphological investigations (Buño, 1992; in prep.) suggest and support that much greater mixing of subspecific genotypes has occurred in these Basque and Catalan populations. In the High Pyrenees the two subspecies only meet in cols below about $2100 \mathrm{~m}$ (the upper altitude limit for $C$. parallelus), whilst at both ends of the chain the lower passes and foothills should make both dispersal and mixing much easier. The development of distinctive nuclear DNA markers, as well as mtDNA ones, means that the extent and causes of these introgressions can now be more clearly addressed.

The expanding distributions of the two subspecies $C$. $p$. parallelus and $C$. p . erythropus would have approached each other after the last ice age from the north and south of the Pyrenees (Hewitt, 1990) and made contact in the high cols as the ice cap on the Pyrenees finally retreated $(\sim 9000 \mathrm{BP})$. The width of the gene clines produced will depend on the interaction of gene flow, selection and colonization (Barton \& Hewitt, 1989; Hewitt, 1993). Since the dispersal and interbreeding will have caused genome mixing for some 9000 generations it is thus of great interest to see that the cpnl-1 marker sequence forms a fairly narrow cline in two adjoining high cols (Peyrelue: $9.7 \mathrm{~km}$, Portalet, $13.3 \mathrm{~km}$ ) and a broader one in another high col towards the east (Quillane: $42.3 \mathrm{~km}$ ). The widths of clines for morphological and behavioural characters through $\mathrm{Col}$ du Portalet range from around $1 \mathrm{~km}$ to $20 \mathrm{~km}(\mathrm{CV} 1=18.52 \mathrm{~km}$, Butlin et al., 1991), so the cpnl-1 locus cline fits nicely into that range and this indicates that a similar suite of forces is operating on this section of the genome as for several other phenotypic characters. However, the same character cline widths at Col de la Quillane are generally smaller $(\mathrm{CV} 1=7.04 \mathrm{~km}$, range: $0.5-16.6 \mathrm{~km})$ and yet, from the data we have at present, the cpnl-1 locus apparently describes a much wider cline $(42.3 \mathrm{~km})$. It has been suggested that the narrower clines at Col de la Quillane have been produced by reduced insect dispersal caused by the more disrupted distribution of suitable habitat at Quillane than at Portalet (Butlin et al., 1991). If this is so, then the cpnl-1 sequence at Quillane must have been affected by a different combination of forces than that at Portalet. We have recently obtained evidence from both cols which indicates that a nucleolar organizing region found on the $\mathrm{X}$ chromosome of C. $p$. parallelus (XNOR), but not on that of $C$. $p$. erythropus, forms a cline that is shifted south of the col centre in both Portalet and Quillane (Ferris et al., 1993). Interestingly, whilst the XNOR cline at Portalet is within the bounds of the other morphological and behavioural clines in this col, the XNOR cline at Quillane is shifted further south outside the otherwise fairly narrow clustering of clines. Clearly we need more detailed data to analyse this difference, but the cpnl-1 sequence and XNOR rDNA sequences seem to have revealed an intriguing and unexpected complexity in the mixing and introgression of these subspecific genomes.

Analysis of the cpnl-1 sequences from several locations across Spain shows that a number of distinct haplotypes exist in different regions (Cooper \& Hewitt, 1993). In particular, populations to the west of the Pyrenees around Picos de Europa have been found to contain a diverse range of haplotypes, some of which were also detected in populations in the Basque region (populations ERRAZ and ICH), whilst populations to the south of the Pyrenees in the Systema Central have sequence similarities with populations from the high central and Catalan end of the Pyrenees. The Spanish haplotype pna12, without the $5 \mathrm{bp}$ insertion, was found in populations in the high central Pyrenees (PAR and FOR) but was absent in the Col du Portalet and adjacent cols in the High Pyrenees. In addition, a second haplotype pna18 (Cooper \& Hewitt, 1993) was detected in several populations towards the Catalan end of the Pyrenees (LLE and FOR) but was absent in populations towards the Basque end. These regional differences in haplotype diversity suggest that $C$. parallelus colonized the Pyrenees by several expansion routes through Spain after the last glaciation, with at least one major expansion route through central Spain and one route through the north of Spain.

On a technical note, it is important for population genetic analyses to know homozygote and heterozygote frequencies, since this tells us several things about population structure and dynamics, and has clear relevance in hybrid zone studies. In PCR amplification of the $\mathrm{I} 5$ and $\mathrm{I} 0$ alleles it was clear that in some cases both of the alleles were not always amplified (visibly) in individuals that were known to be heterozygous. Stochastic differences in the PCR amplification of DNA fragments may be caused by differences in the quality and quantity of DNA used to initiate the PCR. These factors cannot always be ascertained easily, particularly if the DNA is prepared from old tissue samples or relatively small organisms. When dealing with a single locus amplification, as in our case, these problems can be overcome relatively easily by repeating the procedure several times. However, PCR amplification and analysis of multiple loci, particularly when the molecular bases of allelic differences are not known (for example in the case of RAPDs) may prove extremely difficult to interpret. We therefore suggest 
that great care should be taken in the use of such procedures for the analysis of population structure and dynamics.

\section{Acknowledgements}

We are most grateful to the EC and NERC for funding this work, to Roger Butlin for GENSTAT clinal analysis of the data, and to Colin Ferris and Sonia Virdee who helped with collecting insects. We also thank Diane Alden for preparing figures and Geoff Eagles for help with DNA extractions.

\section{References}

BARTON, N. H. AND GALE, K. S. 1993. Genetic analysis of hybrid zones. In: Harrison, R. G. (ed.) Hybrid Zones and the Evolutionary Process, pp. 13-46. Oxford University Press, New York.

BARTON, N. H. AND HEWITT, G. M. 1985. Analysis of hybrid zones. Ann. Rev. Ecol. Syst., 16, 113-148.

BARTON, N. H. AND HEWITT, G. M. 1989. Adaptation, speciation and hybrid zones. Nature, 341, 497-503.

BUÑo, 1. 1992. Estructura de una zona hibrida centre Chorthippus parallelus parallelus y Chorthippus parallelus erythropus (Orthoptera: Acrididae) en el Pirineo Occidental. Thesis, Universidad Autonoma de Madrid, Spain.

BUTLIN, R. K. AND HEWITT, G. M. 1985a. A hybrid zone between Chorthippus parallelus parallelus and Chorthippus parallelus erythropus (Orthoptera: Acrididae): morphological and electrophoretic characters. Biol. J. Linn. Soc., 26, 269-285.

BUTLIN, R. K. AND HEWITT, G. M. 1985b. A hybrid zone between Chorthippus parallelus parallelus and Chorthippus parallelus erythropus (Orthoptera: Acrididae): behavioural characters. Biol. J. Linn. Soc., 26, 287-299.

BUTLIN, R. K. AND RITCHIE, M. G. 1991. Variation in female mate preference across a grasshopper hybrid zone. J. Evol. Biol., 4, 227-240.

BUTLIN, R. K., RITCHIE, M. G. AND HEWITT, G. M. 1991. Comparisons among morphological characters between localities in the Chorthippus parallelus hybrid zone (Orthoptera: Acrididae). Phil. Trans, R. Soc. B., 334, 297-308.
COOPER, S. J. B. AND HEWITT, G. M. 1993. Nuclear DNA sequence divergence between parapatric subspecies of the grasshopper Chorthippus parallelus. Insect Mol. Biol., 2, $185-194$.

FERRIS, C., RUBIO, J. M., SERRANO, L., GOSALVEZ, J. AND HEWITT, G. M. 1993. One way introgression of a subspecies sex chromosome marker in a hybrid zone. Heredity, 71, 119-129.

GOSÁLVEZ, J., LÓPEZ-FERNANDEZ, C., BELLA, J. L., BUTLIN, R. K. AND HEWITT, G. M. 1988. A hybrid zone between Chorthippus parallelus parallelus and Chorthippus parallelus erythropus (Orthoptera: Acrididae): chromosomal differentiation. Genome, 30, 656-663.

HARRISON, R. G. 1990. Hybrid zones: windows on evolutionary process. Oxford Surv. Evol. Biol., 7, 69-128.

HARRISON, R. G. 1993. Hybrid Zones and the Evolutionary Process. Oxford University Press, New York.

HEWITT, G. M. 1988. Hybrid zones - natural laboratories for evolutionary studies. Trends Ecol. Evol., 3, 158-167.

HEWITT, G. M. 1990. Divergence and speciation as viewed from an insect hybrid zone. Can. J. Zool., 68, 1701-1715.

HEWITT, G. M. 1993. Postglacial distribution and species structure: lessons from pollen, insects and hybrid zones. In: Leeds, D. R. and Edwards, D. (eds) Evolutionary Patterns and Processes, pp. 97-123. Linnean Society of London, Academic Press, London.

HEWTT,, G. M., BUTLIN, R. K. AND EAST, T. M. 1987. Testicular dysfunction in hybrids between parapatric subspecies of the grasshopper Chorthippus parallelus. Biol. J. Linn. Soc., 31, 25-34.

SAMBROOK, J., FRITSCH, E. F. AND MANIATIS, T. 1989. Molecular Cloning: A Laboratory Manual, 2nd edn. Cold Spring Harbor Laboratory, Cold Spring Harbor, NY.

SZYMURA, J. M. AND BARTON, N. H. 1986. Genetic analysis of a hybrid zone between the fire-bellied toads, Bombina bombina and $B$. variegata, near Cracow in Southern Poland. Evolution, 40, 1141-1159.

SZYMURA, J. M. AND BARTON, N. H. 1991. The genetic structure of the hybrid zone between the fire-bellied toads Bombina bombina and $B$. variegata: comparisons between transects and between loci. Evolution, 45, 237-261.

VIRDEE, S. R. AND HEWITT, G. M. 1990. Ecological components of a hybrid zone in the grasshopper Chorthippus parallelus (Zetterstedt) (Orthoptera: Acrididae). Bol. San. Veg. Plagas (fuera de serie), 20, 299-309. 